\title{
Los intereses creados
}

\section{The bonds of interest}

\author{
Eugenio Matijasevic. Bogotá, D.C. (Colombia)
}

En 1936, al estallar la guerra civil española, Don Jacinto Benavente y Martínez, premio Nobel de literatura en 1922 (1), fue evacuado de Madrid a Valencia, en donde el legítimo gobierno republicano había instalado la capital luego del alzamiento de los nacionalistas de Franco. Allí permanecería hasta la victoria del bando sublevado en 1939. En el intervalo, en una entrevista que concedió en 1938 al diario comunista francés L'Humanité, declaró que preferiría "caer de inanición, o morir aplastado por las bombas, antes que postrarse a los pies de los invasores". Sin embargo, en 1939, cuando llegaron "los invasores", Benavente esperó con aire digno el ingreso triunfal a la ciudad del General Aranda, director del Cuerpo de Ejército de Galicia, y al verlo se le abrazó trémulo diciéndole: " $¡ Y a$ sabe usted, mi general!, ¡me obligaron!, ¡me obligaron!” (2). Lo cierto es que, con 70 años y siendo ya proverbial su ambigüedad política, había tratado durante esos años de la guerra civil de congraciarse con los republicanos acomodándose a cualquiera de los partidos políticos que permanecieron fieles a la República, pero, puesto que los comunistas y los socialistas contaban en sus filas con suficientes figuras intelectuales como para querer a su lado al ambiguo Benavente, este tuvo que limitarse a colaborar, esto sí abiertamente, con la prensa anarquista.

Este es sólo un ejemplo, entre muchos, de las múltiples volteretas que dio este saltimbanqui de los principios políticos en el circo de la Realpolitik. A finales del siglo XIX y comienzos del XX se había ido lanza en ristre en sus primeras obras contra el cinismo, la doble moral y la crueldad de los poderosos de España y de la tierra (3). Esto no fue óbice para que en la primera década del siglo XX, habiendo probado las mieles del éxito (fama popular y pesetas incluidas) se alejara de la vanguardia literaria e intelectual de su época que no le perdonó "esta cesión de su talento a un arte que es, además, negocio" (4). Durante la primera guerra mundial se declaró abiertamente a favor de los alemanes en su Manifiesto Germanófilo (5). En 1918 fue diputado a Cortes por Madrid apoyado por los conservadores de Maura, y "su labor como diputado fue nula" (6). Durante la dictadura de Primo de Rivera, precursor del fascismo español, fue consentido por el régimen (y viceversa) y fue premiado por ello con la Gran Cruz de Alfonso XII, homenaje que agradeció con un discurso en el que no perdió la ocasión de atacar a los intelectuales españoles que estaban en contra de la monarquía y la dictadura (que eran casi todos): "Y yo me he preguntado muchas veces: ¿Para que querrán más libertad esos intelectuales? Porque bien sabe Dios que [...] yo no he descubierto en sus escritos grandes novedades ni grandes osadías de pensamiento, ni sé que ninguno de ellos haya aportado iniciativa alguna salvadora para la gobernación del Estado" (7) al tiempo que se vanagloriaba de ser un monárquico medular: "Como creo que no hay programa radical ni reforma razonable y justa que sea incompatible con la Monarquía, y que nada puede edificarse sin solidez, sin fundamento en la tradición y en la historia, soy monárquico porque soy español". En los últimos años de la Dictadura cambió su posición frente al régimen ante el hecho de que dos de sus obras, Pepa Doncel y Para el Cielo a los Altares, fueron censuradas supuestamente por la posibilidad de que su representación generara desórdenes; su respuesta no se hizo esperar y estaba en los antípodas de los monárquicos: "dentro de algún tiempo el mundo será socialista o no será nada. Si alguna vez hubiese un gobierno de izquierdas, jamas se hubieran quejado de la estrechez de mi criterio. Se dice que hay en España un problema clerical. No es cierto. Hay un problema de tolerancia de educación. [...] Se dice que el
Dr. Eugenio Matijasevic: Editor General Acta Médica Colombiana. Bogotá, D.C. (Colombia). E-mail: eugenio.matijasevic@gmail.com Recibido: 14/XII/2015 Aceptado: 14/XII/2015 
clericalismo tiene la culpa del atraso de España. ¿No será que el atraso de España tiene la culpa del clericalismo?" (8). Al comenzar la Segunda República temperó un poco su posición y abogó por la defensa integral de la patria sin distingo de colores políticos, derechas o izquierdas (9). En 1932 viajó durante unos meses por la Rusia soviética y en 1933 fundó con otros intelectuales la Asociación de Amigos de la Unión Soviética (10). En 1935, sin embargo, lleno de nostalgias primorriveristas y pensando que la República se venía abajo, hizo un discurso rabiosamente antirrepublicano en el que acusó a los socialistas que conformaban el Directorio de la República de haber "llevado al fracaso a su partido pos sus alianzas con comunistas y separatistas" y aprovechó la ocasión para atacar acerbamente una de las tesis irrenunciables de los comunistas: “¡Dictadura del proletariado! ¡Qué farsa trágica[...]! No les dirán que esa dictadura del proletariado es una dictadura burocrática de una pequeña parte del proletariado; que la otra, la mayor, más proletaria que nunca, se quedará con la ilusión y la esperanza de que alguna vez le toque el premio de la lotería de la revolución" (2). Lo cual no le impediría, ya en Valencia y en plena Guerra Civil, declararse a favor sin ambages de otra de las tesis fundamentales del comunismo, el rechazo a la propiedad privada: "La mayor dificultad que habrá de vencer la gran revolución del proletariado en España [...] será la de sustituir el instinto egoísta de la propiedad individual por el más amplio egoísmo de la propiedad colectiva. Éste debe ser el gran egoísmo de los hombres en lo futuro; ésa debe ser la gloria de esta revolución, la única verdadera y grande que ha habido en España y de la que todos debemos mostrarnos dignos y orgullosos" (2).

Terminada la Guerra Civil y a pesar de haber presidido en Valencia el desfile de la victoria desde la tribuna de honor, los nuevos amos del poder, al regresar a Madrid, lo condenaron por un buen tiempo al ostracismo, hasta que consideraron que, de alguna manera, había lavado sus deslices izquierdistas y de nuevo volvió a ver representadas sus obras (11).

Muchos consideran que Benavente es el ejemplo indiscutible del escritor acomodaticio y carente de principios políticos (a no ser que pueda considerarse un principio la falta de escrúpulos a la hora de cambiar de principios según hacia dónde soplen los mejores vientos económicos o en qué árbol haya mejor sombra contra la adversidad). Otros jueces, no tan severos, consideran que simplemente fue un hombre de su tiempo, víctima de las cambiantes circunstancias políticas de la época y que, si bien no es el más preclaro de los defensores de principios políticos, no hay razón para execrarlo y mucho menos para que sea excluido del Parnaso de la literatura española como le ha ido ocurriendo en los últimos decenios. Otros más, adoptando una posición intermedia, aceptan que aunque fue producto de los tiempos que le tocó vivir, no es posible olvidar que, sin haber abjurado nunca de sus principios, otros muchos escritores de su talla, o incluso por encima de su talla, que vivieron los mismos tiempos, murieron fusilados (Federico García Lorca es un buen ejemplo), murieron en las cárceles franquistas (Miguel Hernández es otro buen ejemplo) o murieron en el exilio sin haber visto nunca de nuevo su patria (Antonio Machado es sólo uno de miles de ejemplos).

Estos mismos aceptan también que fue un buen escritor, con altibajos como tantos, sin olvidar que la obra de todo buen escritor debe mucho a sus tiempos y a su ideario político. Sin embargo todos, Tirios y Troyanos, están de acuerdo en que Los Intereses Creados es su mejor obra (12) y casi ninguno pone en duda que se trata de una de las grandes obras de la literatura española del siglo XX.

Lo cierto es que Benavente demuestra en ella un profundo conocimiento de las motivaciones que encierra el alma humana, utilizando para ponerlas en escena recursos provenientes de la Commedia dell'Arte italiana (con sus clásicos personajes Polichinela, Arlequín, Colombina, Pantalón, El Doctor, El Capitán, La Señora, más otros de la factura del propio Benavente), del teatro de guiñol [Benavente mismo califica Los Intereses Creados en su prólogo como "farsa guiñolesca" (13), es decir, derivada de alguna manera del guiñol o teatro de fantoches, que no es más que un teatro muy español, pero de origen francés, de títeres y marionetas] y de la novela picaresca española del Siglo de Oro. Para quienes no la han visto representada, está disponible en la red una excelente producción del Teatro Español de Madrid dirigida por Gustavo Pérez Puig (14).

Allí el avisado espectador podrá ver como Leandro y Crispín, dos redomados pícaros que no tienen dónde caerse muertos, llegan en los albores del siglo XVII a una ciudad italiana (de cuyo nombre el autor no quiere acordarse) y se hacen pasar, respectivamente, por un rico gentilhombre (enviado a la ciudad para cumplir con una misión secreta) y su criado. Se presentan en la hostería de la plaza principal de la ciudad y consiguen alojamiento sin adelantar dinero alguno, pues Crispín asegura que su amo es tan acaudalado que no deben importunarlo con pequeñeces, mas adelante pagará con creces.

Adulando un poco aquí y un tanto más allá, mintiendo siempre, Crispín va tejiendo una entramada red de préstamos y de favores (de "intereses" los llama él) en la que, a cuenta del supuesto caudal de Leandro, van quedando atrapados todos aquellos que tienen que ver con la hostería.

Cuando Crispín se entera de que Polichinela, el hombre más rico de la ciudad, va a asistir con su hija Silvia a una fiesta en la hostería organizada por Doña Sirena y Colombina, trama con Leandro la manera de enamorar a Silvia para conseguir de Polichinela, a través de su hija, el dinero necesario para pagar la cadena de deudas en la que andan embrollados Leandro y Crispín y en la que otros personajes sin dinero (el Capitán, Arlequín, Colombina, Doña Sirena, etc.) han terminado también enredados.

Durante la fiesta Crispín reconoce en Polichinela a un antiguo compañero de cárcel que, gracias a negocios no muy santos (razón por la que todos le odian), se ha encumbrado 
en la ciudad. Como estaba planeado, Silvia se enamora de Leandro, pero, contra toda predicción, también Leandro se enamora de Silvia.

Polichinela se da cuenta de que Leandro es un vividor, un discípulo aventajado de Crispín, el verdadero amo del enredo. Todos los demás se han dado cuenta también, poco a poco, de que la tan cacareada riqueza de Leandro no existe, pero los lazos de "intereses creados" que Crispín ha ido urdiendo y apretando alrededor de todos y cada uno de los personajes (de todas las clases sociales, ricos y pobres), hacen que nadie se atreva a negarse a ayudar al "amo" Leandro y a su "criado" Crispín so pena de que todo el tinglado se derrumbe, llevando la situación a un limite en el que todos terminarían perdiendo.

Leandro, enamorado, finalmente le descubre a Silvia toda la trama en la que él y Crispín han estado "trabajando" tan arduamente. Por su parte, Crispín apuesta todo a que lo que Polichinela más teme es que Silvia huya con Leandro y que todos se enteren de que su hija se fue con un vividor, arrastrando al lodo su fama (y con ella sus negocios); en lugar de ello preferiría compartir con ellos su fortuna aprobando un casamiento. En el final, "feliz" si se quiere pero profundamente inmoral, todos presionan a Polichinela para que conceda la mano (y la dote) de Silvia a Leandro. Polichinela acepta, con la condición de que Crispín se aleje para siempre de Leandro, y todos obtienen su parte.

Antes de caer el telón, Silvia se dirige a los espectadores para recordarles que han asistido a la representación de una farsa: "Y en ella visteis, como en las farsas de la vida, que a estos muñecos, como a los humanos, muévenlos cordelillos groseros, que son los intereses, las pasioncillas, los engaños y todas las miserias de su condición: tiran unos de sus pies y los llevan a tristes andanzas; tiran otros de sus manos, que trabajan con pena, luchan con rabia, hurtan con astucia, matan con violencia. Pero, entre todos ellos, desciende a veces del cielo al corazón un hilo sutil, como tejido con luz de sol y con luz de luna: el hilo del amor".

Esta del amor, sin embargo, y a pesar de la intención aparente del autor, no es la moraleja que se deduce de la obra. En esta redistribución de bienes (no se puede hablar de dolo) llevada a cabo de manera maestra por Crispín, éste lo único que ha hecho es "crear intereses" y convertir en marionetas a todos aquellos que se han dejado atrapar en esa red de "intereses creados", cuyos hilos sabe él mover tan hábilmente. Por ello, la moraleja, de un cinismo atroz, es otra, y había sido declarada por Crispín de manera perfecta y sucinta un poco antes del monólogo de cierre de Silvia: "Para salir adelante con todo, mejor que crear afectos es crear intereses".

En castellano empleamos el vocablo "interés" en muy diversas circunstancias. De acuerdo con el Diccionario de la Real Academia Española (DRAE), lo hacemos en ocasiones para referirnos al provecho, la utilidad o la ganancia que podemos obtener de algún bien, otras veces para referirnos al valor de algo o para hacer referencia al lucro producido por el capital o, siempre en plural, para hacer referencia a los bienes que posee quien habla ("mis intereses"). También se utiliza, de acuerdo con el DRAE, de manera más abstracta, para referirnos a una "inclinación del ánimo hacia un objeto, una persona, una narración, etc.” o para hacer mención de una determinada "conveniencia o beneficio en el orden moral o material" (15).

Es sobre todo a estas dos últimas acepciones a las que nos remitimos cuando hablamos de "conflicto de intereses", expresión en la que "conflicto" se entiende, de acuerdo (otra vez) con el DRAE, no sólo como "combate, lucha, pelea, enfrentamiento armado", sino también (en sus otras dos acepciones) como "apuro, situación desgraciada y de difícil salida" y "problema, cuestión, materia de discusión" (16).

En inglés, la expresión equivalente a "conflicto de intereses", de la cual probablemente se deriva la expresión en castellano, es conflict of interest. Sin el influjo de dicha expresión inglesa quizás en castellano hubiésemos preferido la expresión tan cara a Don Jacinto Benavente, y desde antaño establecida, de "intereses creados". Pero pudo menos el genio del idioma que la fuerza de las publicaciones en inglés referidas al conflict of interest y la expresión "conflicto de intereses" ha tomado en castellano el sentido de la expresión inglesa, mientras que la expresión "intereses creados" quedó, según el DRAE, para referirse a aquellas "ventajas, no siempre legítimas, de que gozan varios individuos, y por efecto de las cuales se establece entre ellos alguna solidaridad circunstancial que puede oponerse a alguna obra de justicia o de mejoramiento social" (17).

Conflict of interest, tanto en inglés británico (de acuerdo con el Oxford Dictionary) (18) como en inglés norteamericano (de acuerdo con el Merriam-Webster Dictionary) (19), se emplea con el segundo término de la expresión en singular, como si se tratara de un conflicto, en el sentido meramente emocional, al interior de un interés que hemos depositado en cierto aspecto de nuestras vidas. En castellano, desde el punto de vista conceptual, la expresión "conflicto de intereses" es más clara por el uso permanente del plural para el segundo término de la expresión, quedando establecido mediante ella y de manera precisa que existe, utilizando las definiciones del DRAE, un apuro, una situación de difícil salida, un problema, un interrogante materia de discusión, como consecuencia de la existencia simultánea de dos (o más) inclinaciones del ánimo hacia un objeto, una persona, una narración, etc. y que, además, parece que dichas diferentes inclinaciones del ánimo o son por completo incompatibles o simplemente pugnan entre sí de tal manera que se genera el conflicto.

La expresión "conflictos de interés", con el segundo término de la expresión en singular, que a veces se utiliza en la literatura médica en castellano, es incorrecta. Para el genio del idioma castellano, la cuestión es clara: existe un conflicto entre dos o más intereses contradictorios, pero no es posible que existan varios conflictos al interior de un sólo interés. Por ello "conflictos de interés" sería un barbarismo o una traducción macarrónica de conflicts of interest, el plural en 
inglés de conflict of interest. El plural de conflict of interest no es conflict of interests ni conflicts of interests, sino, como se mencionó, conflicts of interest, pues en inglés, como en castellano, no es infrecuente que al construir el plural de un nombre compuesto el efecto se logre pluralizando sólo el primer componente del nombre compuesto (como ocurre por ejemplo con términos como brother in law que se pluraliza a brothers in law pero nunca a brother in laws o a brothers in laws; de igual manera a como ocurre en castellano con algunos sustantivos compuestos como el niño prodigio o el sofá cama, cuyos plurales son, respectivamente, los niños prodigio y los sofás cama y no los niños prodigios o los sofás camas) (20). En nuestra lengua el plural de conflicto de intereses es obviamente conflictos de intereses.

El International Committee of Medical Journal Editors (ICMJE) cuyas Recommendations for the Conduct, Reporting, Editing, and Publication of Scholarly Work in Medical Journals) (21) Acta Médica ha suscrito (22) utiliza siempre la expresión en plural Conflicts of Interest.

Posiblemente la mejor definición de Conflict of Interest sea la que Dennis F. Thompson dio en 1993 en The New England Journal of Medicine (NEJM): A Conflict of interest is a set of conditions in which professional judgment concerning a primary interest (such as a patient's welfare or the validity of research) tends to be unduly influenced by a secondary interest (such as financial gain) (23) ("Un conflicto de intereses es un conjunto de condiciones en las cuales el juicio profesional concerniente a un interés primario (tal como el bienestar de un paciente o la validez de una investigación) tiende a ser influido de manera indebida por un interés secundario (tal como una ganancia financiera)".

Dennis F. Thompson no es médico. Se graduó con honores en Filosofía, Política y Economía en el Balliol College de la Universidad de Oxford y obtuvo un Ph. D. en Filosofía Política en la Universidad de Harvard en 1968. Enseñó en la Universidad de Princeton durante 18 años antes de retornar a Harvard en 1986. En la actualidad es Professor of Government y Alfred North Whitehead Professor of Political Philosophy en la Facultad de Artes y Ciencias de Harvard. Es, además, el Director Fundador del University Center for Ethics and the Professions con sede en dicha Universidad, ha sido miembro del National Institute of Medicine's Committee on Conflict of Interest y ha sido asesor de la American Medical Association y del Department of Health and Human Services de los Estados Unidos de América para nombrar, entre las muchas que ha asesorado, dos instituciones que tienen que ver directamente con la salud (24). Ha escrito y publicado 13 libros, casi todos ellos dirigidos a analizar y resolver dificultades planteadas al interior de la ética profesional en diversas áreas de la actividad humana, en especial en la salud, el gobierno y la política (quizás el más trascendental en este campo sería Restoring Responsibility: Ethics in Government, Business, and Healthcare) (25); 35 capítulos de libros y 47 artículos en revistas avaladas por pares como el ya mencionado en NEJM.
El artículo en cuestión no es un editorial, es un Sounding Board, nombre con el que NEJM publica, hasta la fecha, artículos de opinión escritos por expertos en determinados temas y cuyo contenido, de acuerdo con el comité editorial de la revista, debería ser motivo de reflexión y discusión más amplia ente los lectores. Un Sounding Board de NEJM debería servir para difundir y multiplicar una cierta idea que se considera básica para el ejercicio profesional o debería servir para precisar y rescatar para su uso cotidiano conceptos que se han ido difuminando en dicho ejercicio tornándose ambiguos y por tanto inservibles. Tal era la intención de un Sounding Board sobre conflicts of interest escrito por quien en ese momento podría considerarse el scholar que más había indagado y trabajado en el asunto.

El término Sounding Board, en el sentido que quiere darle NEJM, es difícil de verter al castellano. En inglés se le da este nombre a la estructura de madera que, a manera de un techo de diversas formas, se coloca sobre los púlpitos. En realidad no es un techo, es un dispositivo de ingeniería de sonido, primitivo si se quiere, pero altamente eficaz, encargado de evitar que la voz de quien habla desde el púlpito se pierda en las alturas de la arquitectura de los templos permitiendo que "baje" hacia los fieles oyentes con mayor sonoridad y claridad [de ahí su nombre en francés: abat-voix (26), "bajador de la voz"]. En castellano se llama sombrero del púlpito o tornavoz, aunque este nombre también se aplica en el teatro a la concha del apuntador desde la cual éste recuerda a los actores los fragmentos de diálogo que hayan podido olvidar (27). El caso es que en inglés el término sounding board ha pasado a utilizarse para designar, de manera figurativa, cualquier dispositivo o entidad que ayude a propagar opiniones o declaraciones y para designar también a cualquier persona o grupo de personas con quienes uno pone a prueba una idea u opinión con el fin de evaluarla (28). La similitud de sounding board con soundboard, que es el nombre de la caja de resonancia en los instrumentos musicales de cuerdas (29), no es sólo lexicográfica sino también conceptual. De hecho el Oxford Spanish Dictionary propone que cuando el término sounding board se esté aplicando en inglés a ideas (y no al objeto material que en castellano denominamos sombrero de púlpito) se traduzca al castellano, de manera figurada, como caja de resonancia y trae buenos ejemplos en los que dicha traducción funciona a la perfección (30).

Precisamente en una de estas "cajas de resonancia" de NEJM es que apareció en 1993 el artículo de Thompson. Pero para llegar al verdadero origen del interés sobre el asunto de los conflictos de intereses en las publicaciones periódicas biomédicas, habría que remontarse casi una década atrás a un editorial de Arnold S. Relman, en aquel entonces editor de NEJM: Dealing with Conflicts of Interest (haciéndonos cargo o enfrentando los conflictos de intereses) (31). En dicho editorial Relman aboga porque "los autores reconozcan en una nota a pié de página todas las fuentes de financiamiento del trabajo de investigación que están enviando para publicación al igual que cualquier asociación 
directa con negocios, tales como ser empleado de una corporación con intereses en el trabajo de investigación que se va a publicar". Esto debido a que "la confianza es un elemento fundamental en el emprendimiento de la investigación" y a que "en los años recientes, a medida que las posibilidades comerciales de nuevos descubrimientos biomédicos se han vuelto cada vez más atractivas, las conexiones [entre la industria y los científicos de la medicina académica] se han vuelto más omnipresentes, complejas y problemáticas". En este editorial Relman estableció por vez primera una política editorial en una revista biomédica con respecto a los conflictos de intereses (32).

Más adelante, en 1990, Relman exigió que los autores de editoriales o de artículos de revisión en NEJM no tuvieran intereses financieros en compañías cuyo producto (o el producto de una empresa competidora) fuera mencionado en el artículo (33). Hasta ese momento la política editorial de NEJM no había hecho diferencia entre los artículos de investigación y los artículos de revisión, simplemente exigía, desde 1984, que los autores declararan sus conflictos de interés independientemente del tipo de artículo en ciernes. A partir de ese momento ni los editoriales ni los artículos de revisión podrían ser escritos por autores con conflictos de interés. La razón que adujo Relman es muy simple: los artículos de investigación aportan datos que los lectores pueden interpretar por sí mismos, mientras que en los editoriales y en las revisiones de tema los autores utilizan su propio criterio para citar e interpretar la literatura biomédica y los lectores tienen que confiar a ciegas en la supuesta objetividad de dichos autores.

El siguiente editor de NEJM, Jerome P. Kassirer, mantuvo esa política (32). De hecho, el Sounding Board de Thompson, ya mencionado, viene acompañado en el mismo número de NEJM de un editorial sobre el tema y las políticas de NEJM al respecto firmado tanto por Kassirer como por Marcia Angell (a la sazón editor en jefe y editora ejecutiva, respectivamente, de NEJM) (34).

En 1999, Kassirer renunció de manera irrevocable a su cargo del editor en jefe de NEJM porque el Committee on Administration and Management de la Massachusetts Medical Society, la propietaria de NEJM, insistió en utilizar el nombre y el logo de la revista para el mercadeo de otros productos de la sociedad sobre información en salud. Kassirer esgrimió la tesis de que era "engañoso, utilizar un nombre de marca tan respetado para promover otros productos simplemente porque la Sociedad es la propietaria de la revista" (35). Lo sucedió Marcia Angell como editora en jefe interina. Su trabajo fue arduo, pero logró imponer el criterio de que el buen nombre de una publicación científica periódica no puede ser utilizado para mercadear otros productos, así estos estén relacionados con la salud, insistiendo en que el editor de una revista y su comité editorial deben disfrutar de completa independencia editorial para poder asumir la completa responsabilidad por el contenido y la política editorial de la revista (36).
Marcia Angell continuó como editora en jefe interina hasta el año 2000, cuando retiró su candidatura para el cargo de editora en jefe aduciendo que se dedicaría a escribir (en 2005 publicó, en efecto, The Truth About the Drug Companies: How They Deceive Us and What to Do About It, libro del cual existe una excelente traducción en castellano) (37). La sucedió Jeffrey M. Drazen.

El nuevo editor modificó en 2002, ablandándola y dejándola prácticamente inservible, la política sobre editoriales y revisiones de tema que se había mantenido bajo las direcciones de Relman, Kassirer y Angell: "Comenzando con esta edición de la revista, hemos modificado la declaración en información a los autores para que se lea como sigue: dado que la esencia de los editoriales y los artículos de revisión es la selección de la literatura, la revista espera que los autores de tales artículos no tengan ningún interés financiero significativo en una compañía (o en su competencia) que fabrique un producto discutido en el artículo. La adición de la palabra 'significativo' reconoce que no todos los lazos financieros son iguales" (38). No quedó muy claro en este editorial qué significaba exactamente "significativo", pues se dejaba en la práctica al criterio de los editores de la revista la decisión de si unos ciertos lazos financieros entre quien escribe un artículo de revisión o un editorial y una compañía comercial son o no importantes para que los lectores puedan mantener la confianza en lo que publica la revista: "Nosotros como editores somos responsables de sopesar los hechos disponibles con respecto a cada posible autor y con respecto a tomar las decisiones que consideramos aportarán la mejor información científica y medica a la revista". Lo que sí afirma Drazen es que va a garantizar que ninguno de los editores de NEJM encargado de la toma de dichas decisiones tenga relaciones financieras con compañía biomédica alguna.

Desde 2012 NEJM ha venido publicando de manera ocasional una sección que denomina Medicine and Society. Hasta octubre de 2015 ha publicado 16 artículos en este formato. Al parecer se trata de artículos encargados a quienes la revista denomina "national correspondents" (39). En los números del 7, el 14 y el 21 de mayo de 2015 apareció en tres partes un artículo de Lisa Rosembaum supervisado o aprobado por Debra Malina, Perspective Editor de NEJM, dedicado al tema de los conflictos de intereses (o si se prefiere: aparecieron tres artículos sobre el mismo tema) en el que con un estilo ágil, persuasivo, intrincado, a veces laberíntico pero siempre retórico en la medida a que apela de manera sutil a las emociones del lector, la emprende de manera revisionista en contra de los procesos de regulación de los conflictos de intereses y a favor de la libertad absoluta en las relaciones entre médicos e industria farmacéutica. Los títulos de los artículos hablan por sí solos: Conflicts of interest: Reconnecting the Dots - Reinterpreting Industry-Physician Relations ("Conflictos de intereses: Reconectando los puntos: reinterpretando las relaciones industria-médicos”) (40), Conflicts of interest: Understanding Bias - The Case for Careful Study ("Conflictos de intereses: Comprendiendo el 
sesgo: el caso para un cuidadoso estudio") (41) y Conflicts of interest: Beyond Moral Outrage - Weighing the TradeOffs of COI Regulation ("Conflictos de intereses: Más allá de la indignación moral: sopesando las transacciones [en el sentido de sacrificar algo en favor de un mayor beneficio] en la regulación de los conflictos de intereses") (42). Lisa Rosembaum es cardióloga y trabaja como tal en el Brigham and Women's Hospital en Boston. Escribe, además, en un ameno estilo periodístico, en The New Yorker (43), la revista publicada por el grupo Condé Nast, con artículos de literatura, crítica social, comentarios políticos, muy querida en Nueva York y famosa en el resto del mundo por sus portadas y por sus caricaturas. Ese mismo estilo periodístico es el que ha dado a sus diatribas contra la regulación de los conflictos de intereses en NEJM. Escribe bien, pero hay que leerla para entender que su laissez faire, laissez passer con respecto a los conflictos de intereses significa un revés para las publicaciones científicas periódicas en la larga lucha de estas para que lo que se publica como ciencia sea ciencia.

A diferencia de NEJM, British Medical Journal (BMJ), otra de las revistas de más alto rango entre las publicaciones biomédicas, ha aplicado una política de Zero tolerance on education articles with financial links to industry ("cero tolerancia a los artículos educativos con lazos financieros con la industria") (44). Por "artículos educativos" BMJ entiende todos aquellos artículos que no son producto directo de una investigación o de un meta-análisis de la literatura biomédica sino el producto de una indagación por parte de un autor o autores sobre un determinado tema que tiene como fin promover el conocimiento o dejar sentados ciertos valores o criterios. Caben aquí todos aquellos artículos que conocemos como editoriales, revisiones de tema, actualizaciones, estados del arte, etc. en los que, como diría Relman, los datos y las cifras no están directamente a disposición del lector sino que han sido "editados" previamente a través del filtro subjetivo del autor o autores.

Los conflictos de intereses están presentes de manera continua en nuestra vida cotidiana, en las más diversas circunstancias, sin que sea posible escapar a ellos. Con frecuencia la vida nos obliga a tomar una decisión eligiendo uno de los aspectos en pugna, con lo que nos decantamos por uno sólo de ellos y obramos en consecuencia. Decimos en tal caso que hemos resuelto el conflicto. Pero existen circunstancias en las que no es posible resolver el conflicto y, por el contrario, la situación conflictiva se mantiene sin que podamos renunciar a ninguna de las partes en pugna. En tal caso la producción del conocimiento (y las publicaciones científicas periódicas) no piden sacrificios extremos e imposibles, piden solamente que haya transparencia con respecto al conflicto.

El coletazo revisionista que ha dado NEJM con respecto a los conflictos de interés en las mencionadas publicaciones de su sección Medicine and Society es por completo ajeno al espíritu de las publicaciones científicas periódicas. Es una vuelta atrás, no en política, como las volteretas de Don
Jacinto Benavente, sino en la producción del conocimiento y en la difusión del conocimiento producido (aunque esto también es política). Esperamos que la opinión prevalente en los citados artículos de Lisa Rosembaum no termine traducida en modificaciones de la política editorial de NEJM o en modificaciones en sus instrucciones a los autores. $\mathrm{Si}$ esto último tuviese lugar estaríamos frente a una regresión abominable en la que los "conflictos de intereses" (que aceptamos, pero queremos verlos abiertos, transparentes) se verían sustituidos, ahora sí, por "intereses creados", con miles de Crispines rondando alrededor de las investigaciones biomédicas, de las publicaciones biomédicas y de los lectores, tratando de apretar aun más los lazos comerciales, de publicidad y mercadeo, alrededor de la producción y difusión del conocimiento que no sería ya conocimiento sino publicidad travestida de ciencia.

Acta Médica Colombiana cumple ya 40 años de publicación ininterrumpida. De una época en la que no se declaraban los conflictos de intereses, hemos pasado a otra en que cada autor declara con sus propias palabras cuáles son dichos conflictos, pero, como los lectores habrán observado, no existe uniformidad en la manera de declararlos. El ICJME recomienda, desde hace unos años, un formulario de declaración de conflictos de intereses que busca normalizar dicha declaración haciéndola más uniforme y precisa. A partir del próximo número de Acta Médica Colombiana, además de la declaración de conflictos de intereses general que va en la segunda página del manuscrito original (ver indicaciones a los autores) (22), cada autor o coautor debe enviar una Declaración de Conflicto de Intereses por separado, cuyo formato aparecerá durante el proceso de envío del manuscrito original a través del OJS (45). El formato está diseñado para que el autor o coautor lo imprima, lo complete, lo firme y lo envíe a Acta Médica Colombiana por correo aéreo a la dirección: Carrera 16A \# 77-11.

El propósito de dicha Declaración de Conflicto de Intereses es que cada uno de los autores de un trabajo de investigación enviado para posible publicación a nuestra revista "brinde a los lectores información sobre otros intereses del autor que podrían influir en la manera en que los lectores perciban y entiendan su trabajo" (46). En ningún caso Acta Médica Colombiana va a dejar de publicar un artículo de investigación de buena calidad científica debido a la presencia de conflictos de intereses. Lo único que pide nuestra revista, al igual que todas las publicaciones científicas periódicas, es que el conflicto sea declarado de manera precisa y honesta.

\section{Referencias}

1. Nobel Foundation. Jacinto Benavente - Biographical. Consultado el 20 de octubre de 2015. Disponible en http://www.nobelprize.org/nobel_prizes/literature/laureates/1922/benavente-bio.html

2. Aznar Soler M. República literaria y revolución 1920-1939. Sevilla: Editorial Renacimiento; 2010: 480-524.

3. Gómez-Ferrer Morant G. El discurso de Benavente en la etapa intersecular. Cuadernos de Historia Contemporánea 2003; número extraordinario 1: 85-100. Consultado el 20 de octubre de 2015. Disponible en http://dialnet.unirioja.es/ ejemplar/87853 
4. Lázaro Carreter F. Introducción. En Benavente J. Los Intereses Creados. 21 ${ }^{\mathrm{a}}$ edición. Madrid: Editorial Cátedra; 2011: pp 9-48.

5. Ortiz de Urbina P. La Primera Guerra Mundial y sus consecuencias: la imagen de Alemania en España a partir de 1914. Revista de Filología Alemana 2007; 15: 193-206. Consultado el 20 de octubre de 2015. Disponible en http://dialnet. unirioja.es/servlet/articulo?codigo $=2905394$

6. Muñoz B. La ficha policial de Jacinto Benavente. Artez, revista de las artes escénicas, mayo 2011. Consultado el 20 de octubre de 2015. Disponible en http:// www.revistadeteatro.com/artez/artez169/iritzia/bertamunoz.htm

7. Ayuntamiento de Madrid. Sesión Solemne celebrada por el Ayuntamiento de Madrid bajo la presidencia de S. M. el rey Don Alfonso XIII en honor del excelentísimo Sr. D. Jacinto Benavente el día 1 de marzo de 1924. Madrid: Imprenta municipal; 1924. Consultado el 20 de octubre de 2015. Disponible en http://www. memoriademadrid.es/fondos/OTROS/Imp_24362_ia_407.pdf

8. García Clavel J. Literatura y compromiso bajo la dictadura de Primo de Rivera. Tesis Doctoral. Universidad de Navarra. Departamento de Filología. Programa de doctorado: Literatura hispánica y Teoría de la literatura. Consultado el 20 de octubre de 2015. Disponible en http://dadun.unav.edu/bitstream/10171/37154/1/ Tesis_JavierGarciaClavel.pdf. pp 95-105.

9. Benavente J. La Política y los Intelectuales. En Obras Completas. Tomo XI. Madrid: Editorial Aguilar; 1958: p 37.

10. Garrido Caballero M. Las relaciones culturales hispano-soviéticas (1931-1939). Ayer 2009; 74 (2): 191-217.

11. Trapiello A. Las armas y las letras 1936-1939. Literatura y guerra civil. Barcelona: Planeta;1994: p 347.

12. Gómez García M. Diccionario Akal de Teatro. Madrid: Ediciones Akal; 1997: p 388.

13. Benavente J. Los Intereses Creados. Lázaro Carreter F (Ed). $21^{\text {a }}$ edición. Madrid: Editorial Cátedra; 2011: 126 pp.

14. Benavente J. Los intereses Creados. Pérez Puig G (Director). Teatro Español de Madrid (Productor). Consultado el 20 de octubre de 2015. Disponible en https:// www.youtube.com/watch?v=3hYTNWK3Q28.

15. Real Academia Española. Interés. En Diccionario de la Lengua Española. Vigésima tercera Edición. Madrid: Espasa Libros; 2014.

16. Real Academia Española. Conflicto. En Diccionario de la Lengua Española. Vigésima tercera Edición. Madrid: Espasa Libros; 2014.

17. Real Academia Española. Intereses creados. En Diccionario de la Lengua Española. Vigésima tercera Edición. Madrid: Espasa Libros; 2014.

18. Merriam Webster Dictionary. Conflict of interest. Consultado el 20 de octubre de 2015. Disponible en http://beta.merriam-webster.com/dictionary/conflict\%20 of\%20interest

19. Oxford Dictionaries. Conflict of interest. Consultado el 20 de octubre de 2015 . Disponible en http://www.oxforddictionaries.com/definition/english/conflict-ofinterest

20. Real Academia Española. Consultas lingüísticas: Palabras clave o palabras claves, copias pirata o copias piratas. Consultado el 20 de octubre de 2015. Disponible en: http://www.rae.es/consultas/palabras-clave-o-palabras-claves-copias-piratao-copias-piratas.

21. International Committee of Medical Journal Editors. Recommendations for the Conduct, Reporting, Editing, and Publication of Scholarly Work in Medical Journals. Consultado el 20 de octubre de 2015. Disponible en http://www.icmje. org/icmje-recommendations.pdf

22. Acta Médica Colombiana. Indicaciones a los Autores. Consultado el 20 de octubre de 2015. Disponible en: http://www.actamedicacolombiana.com/info_autores. php?d=Indicaciones \%20para\%20autores\#req

23. Thompson DF. Understanding financial conflicts of interest. N Engl J Med 1993;
329 (8): 573-76.

24. Harvard University. Department of Government. Dennis F. Thompson. Consultado el 20 de octubre de 2015. Disponible en http://scholar.harvard .edu/dft/home

25. Thompson DF. Restoring Responsibility: Ethics in Government, Business, and Healthcare. Cambridge: Cambridge University Press; 2005; 360 pp.

26. Ortolang. Centre National des Ressources Textuelles et Lexicales. En Lexicographie. Abat-voix. Consultado el 20 de octubre de 2015. Disponible en http:// www.cnrtl.fr/definition/abat-voix.

27. Real Academia Española. Tornavoz. En Diccionario de la Lengua Española. Vigésima tercera Edición. Madrid: Espasa Libros; 2014.

28. Merriam Webster Dictionary. Sounding Board. Consultado el 20 de octubre de 2015. Disponible en http://beta.merriam-webster.com/dictionary/sounding $\% 20$ board

29. Merriam Webster Dictionary. Soundboard. Consultado el 20 de octubre de 2015. Disponible en http://beta.merriam-webster.com/dictionary/soundboard

30. Oxford Dictionaries. English-Spanish. Sounding Board. Consultado el 20 de octubre de 2015. Disponible en http://www.oxforddictionaries.com/translate/ english-spanish/sounding-board

31. Relman AS. Dealing with Conflicts of Interest. N Engl J Med 1984; 310 (18): 1182-83.

32. Steinbrook R, Kassirer JO, Angell M. Justifying conflicts of interest in medical journals: a very bad idea. BMJ 2015; 350:h2942. Consultado el 20 de octubre de 2015. Disponible en http://www.bmj.com/content/350/bmj.h2942.

33. Relman AS. New information for authors and readers. N Engl J Med 1990; 323 (1): 56 .

34. Kassirer JP, Angell M. Financial Conflicts of Interest in Biomedical Research. N Engl J Med 1993; 329 (8): 570-71.

35. Kassirer JP. Correspondence. The departure of Jerome P. Kassirer. N Engl J Med 1999; 341 (17): 1319-1313.

36. Angell M. The Journal and its owner - Resolving the crisis. N Engl J Med 1999; 341 (10): 752.

37. Angell M. La verdad acerca de la industria farmacéutica: cómo nos engaña y qué hacer al respecto. Bogotá: Grupo Editorial Norma; 2006: 321 pp.

38. Drazen JM, Curfman GD. Financial associations of authors. N Engl J Med 2002; 346: 1901-02.

39. New England Journal of Medicine. Editors and Publishers. Consultado el 2 de noviembre de 2015. Disponible en http://www.nejm.org/page/about-nejm/ editors-and-publishers.

40. Rosembaum L. Conflicts of interest: Reconnecting the Dots - Reinterpreting Industry-Physician Relations. N Engl J Med 2015; 372 (19): 1860-4.

41. Rosembaum L. Conflicts of interest: Understanding Bias - The Case for Careful Study. N Engl J Med 2015; 372 (20): 1960-3.

42. Rosembaum L. Conflicts of interest: Beyond Moral Outrage - Weighing the Trade-Offs of COI Regulation. N Engl J Med 2015; 372 (21): 2064-2068.

43. The New Yorker. Contributors. All works by a Lisa Rosembaum. Consultado el 15 de noviembre de 2015. Disponible en http://www.newyorker.com/contributors/ lisa-rosenbaum/all.

44. Chew M, Brizzell C, Abbasi K, Godlee F. Medical journals and industry ties. BMJ 2014; 349: g7197.

45. Acta Médica Colombiana. Enviar un artículo vía OJS. Consultado el 15 de noviembre de 2015. Disponible en http://actamedicacolombiana.com/ojs/index. $\mathrm{php} / \mathrm{actamed} / \operatorname{login}$.

46. International Committee of Medical Journal Editors. Conflicts of Interest. Consultado el 20 de octubre de 2015. Disponible en: http://www.icmje.org/ conflicts-of-interest/. 